\title{
Investigation of the Influence of the Synthesized Iron- Carbide Mixture on the Adhesive and Mechanical Properties of Epoxy Composites for Parts of Transport Machines
}

\author{
Andriy Buketov \\ Department of Transport Technologies \\ Kherson State Maritime Academy \\ Kherson, Ukraine \\ buketov.andrey@gmail.com
}

Tetiana Cherniavska

Department of Transport Technologies Kherson State Maritime Academy

Kherson, Ukraine

tanya2181@ukr.net

\author{
Olha Syzonenko \\ Department of Pulse Processing \\ Dispersed Systems, Institute of Pulse \\ Processes and Technologies of NAS of \\ Ukraine, Mykolaiv, Ukraine \\ sizonenko43@rambler.ru \\ Eduard Appazov \\ Department of Innovative Technologies \\ and Technical Means of Navigation \\ Kherson State Maritime Academy \\ Kherson, Ukraine \\ eappazov1@gmail.com
}

\author{
Dmytro Kruglyj \\ Department of Innovative Technologies \\ and Technical Means of Navigation \\ Kherson State Maritime Academy \\ Kherson, Ukraine \\ krughlyidmytro@gmail.com \\ Kostiantyn Klevtsov \\ Department of Transport Technologies \\ Kherson State Maritime Academy \\ Kherson, Ukraine \\ klevtsovk@i.ua
}

\begin{abstract}
Epoxy-diane oligomer ED-20, hardener polyethylene polyamine, and micro dispersed particles of iron-carbide mixture synthesized by high-voltage electric discharge have been used for the formation of Composite Materials (CMs) and protective coatings for the transport industry. The dependence of the adhesive, physical, and mechanical properties and residual stresses of epoxy composites on the content of micro dispersed powders has been studied in this paper. It has been proved that for the formation of a composite material or protective coating with improved adhesion and cohesion properties, the optimal content of particles is $0.5 \mathrm{wt} . \%$ per $100 \mathrm{wt} . \%$ of epoxy oligomer ED-20. Such materials are characterized by increased mechanical strength and the ability to resist static and shock loads, as their properties are significantly increased. The obtained results of the experimental studies of the physical and mechanical properties of composite materials correlate with the studied results of adhesive characteristics, which indicate their veracity.
\end{abstract}

Keywords-epoxy composite; modulus of elasticity; impact strength; flexural stresses

\section{INTRODUCTION}

The development of various industries, including transport, involves the expansion of the scope of structural functional polymeric materials. The use of polymeric epoxy composite coatings is important for the corrosion protection of technological equipment, including parts of transport machines [1-5]. Ensuring the compliance between the properties of materials used in mechanisms and structures in the complex conditions of their operation is one of the most significant

Corresponding author: A. Buketov problems of technological progress nowadays. The current level of production development involves primarily taking into account the economic factor due to the need to develop new effective functional materials. Herewith, it is necessary to make allowance the latest approaches, which are based on the optimization of the components of materials of a specific functional purpose. At the same time, such optimization is carried out according to several criteria, such as adhesive strength, residual stresses, flexural stresses, and impact strength. Today, the potential capabilities of known polymeric materials are far from being fully realized, due to the insufficient analysis of the physicochemical processes during their operation and destruction. In our opinion, only an approach that involves the analysis of properties in a complex will ensure the formation of new gradient composites with specified improved both adhesive and cohesive characteristics.

Authors in $[6,7]$ showed that the creation of new materials with high performance is impossible without understanding the mechanism of interaction at the interface of the phases "protective coating - metal base" and "polymer matrix - filler", which is the basis for the formation of chemical and physical bonds that determine the durability of materials. To implement the above, dispersible filler particles are introduced into the polymer binder. The presence of the active groups on the surface of the additives, which during the polymerization of the matrix form a significant number of bonds per unit volume of polymer is important. In this regard, it is important to preactivate the filler. Authors in $[8,9]$ showed that the use of 
synthesized (including high-voltage electric discharge) powders with particles of insignificant dispersion is perspective. Given this, it is important to conduct a study to determine the optimal content of iron-carbide mixture synthesized by high-voltage electric discharge in the formation of protective polymer coatings to improve the adhesive and mechanical properties of transport vehicle parts.

The aim of the work is to investigate the influence of the content of synthesized iron-carbide mixture on the adhesive and mechanical properties of epoxy composites for the transport industry.

\section{MATERIALS AND METHODS}

Epoxy diane resin ED-20 (GOST 10587-84) was selected for the formation of the polymer matrix. Epoxy resin is a highly viscous transparent liquid that can be cross-linked at room or elevated temperature without external pressure. The ability to cure these resins without the release of by-products provides low shrinkage, high density, and low porosity of materials, which is important when working with composite products and protective coatings based on them in difficult conditions. Polyethylene polyamine - PEPA (TU 6-02-594-70) was selected for curing the epoxy compositions. Hardener PEPA is used for the cross-linking of epoxy resins at room and low temperatures in conditions of high humidity. The composites were crosslinked by introducing the hardener into the composition at a stoichiometric ratio of components at content (wt.\%) - ED-20 : PEPA - $100: 10$. Synthesized Iron-Carbide Mixture (SICM) was used as a microdisperse filler in the experiment. The filler was formed by High-Voltage Electric Discharge (HVED) synthesis. For the HVED synthesis of the filler an experimental stand was used, described in detail in [8, 9]. A mixture of powders of $\mathrm{Fe}(75 \%)$ and $\mathrm{Ti}(25 \%)$ was used as the starting material. During the synthesis, the accumulated energy of a single discharge $\left(W_{1}\right)$ was $1 \mathrm{~kJ}$, and the integrated specific energy of the processing $(W)$ was $25 \mathrm{MJ} / \mathrm{kg}$. Variations can be performed in the process in the distribution of the electric field and plasma formations in the volume of the discharge chamber by using different types of electrode systems. In this work, a 15-point design of the electrode system is used [8]. The use of different electrode systems allowed controlling the distribution of the intensity of the main factors of HVED [9]. Thus, in the case of using a 1-point system, a larger share of the accumulated energy was transformed into shock waves, then the use of a 15-point system allowed increasing the intensity of thermal and current factors. The results of the research showed that as a result of HVED treatment all the treated particles were crushed and their phase composition was changed with the synthesis of high-modulus compounds $\mathrm{TiC}$ and $\mathrm{Fe}_{3} \mathrm{C}$ (Table I).

The technology of forming epoxy composites is as follows. At the initial stage, the epoxy resin was heated to a temperature of $T=353 \pm 2 \mathrm{~K}$, kept during for a time duration of $\tau=20 \pm 0.1 \mathrm{~min}$. At the next stage, the resin was hydrodynamically combined with the dispersed filler for $10 \pm 0.1 \mathrm{~min}$ and then Ultrasonic Processing (USP) of the composition was performed for $1.5 \pm 0.1 \mathrm{~min}$. After cooling the mixture to room temperature ( $\tau=60 \pm 5 \mathrm{~min}$ ), a hardener was introduced and the composition was blending for $5 \pm 0.1 \mathrm{~min}$. The prepared compositions were formed and were polymerized according to the following procedure:

- casting of specimens

- keeping for $12.0 \pm 0.1$ hours at room temperature $(293 \pm 2 \mathrm{~K})$

- heating to $393 \pm 2 \mathrm{~K}$ (at a rate of $v=3 \mathrm{~K} / \mathrm{min}$ )

- keeping at a given temperature during $2.0 \pm 0.05$ hours

- slowly cooling to $293 \pm 2 \mathrm{~K}$.

At the final stage, the specimens were kept for 24 hours in the air at a temperature of $293 \pm 2 \mathrm{~K}$ to internal stress relaxation, which allowed stabilizing the developed materials properties. The following properties of CM were investigated in this work: adhesive strength, residual stresses, flexural stresses, and modulus of elasticity at bending and impact strength.

TABLE I. RESULTS OF THE HVED SYNTHESIS OF THE FILLER

\begin{tabular}{|c|c|c|c|c|c|}
\hline \multirow{2}{*}{ Composition } & \multirow{2}{*}{$\begin{array}{c}\text { Composition } \\
\text { after } \\
\text { treatment }\end{array}$} & \multirow{2}{*}{$\begin{array}{c}\text { Electrode } \\
\text { system }\end{array}$} & \multicolumn{3}{|c|}{$\begin{array}{c}\text { Diameter after } \\
\text { treatment } \boldsymbol{d}(\boldsymbol{\mu} \mathbf{m})\end{array}$} \\
\cline { 4 - 6 } & & $\boldsymbol{d}_{\boldsymbol{m i n}}$ & $\boldsymbol{d}_{\max }$ & $\boldsymbol{d}_{\boldsymbol{a} \boldsymbol{v}}$ \\
\hline $\mathrm{Fe}(75 \%)+$ & $\mathrm{Fe}(70 \%)+$ & & & & \\
$\mathrm{Ti}(25 \%)$ & $\begin{array}{c}\mathrm{TiC}(25 \%)+ \\
\mathrm{Fe} 3 \mathrm{C}(5 \%)\end{array}$ & 15 & $\sim 1$ & 147 & 17 \\
\hline
\end{tabular}

The influence of the content of additives of different nature on the adhesion properties of composites to the metal base was investigated. The destructive tension ("fungal method") was measured with a uniform separation of a pair of glued samples in accordance with ASTM D897-08(2016). The adhesive strength was investigated on an automated tensile testing machine UM-5 at a loading speed of $10 \mathrm{~N} / \mathrm{s}$. The diameter of the working part of the steel specimens was $25 \mathrm{~mm}$. Residual stresses in coatings were determined by the cantilever method according to [10]. Residual stresses $\sigma_{\mathrm{r}}$ were found by:

$$
\sigma_{r}=\frac{H E \delta^{3}}{3 L^{3}\left(\delta+\delta^{*}\right) \delta^{*}}
$$

where $H$ is the substrate deflection from the initial position (m), $E$ is the elasticity modulus of the substrate $\left(E=2.1 \times 10^{8} \mathrm{~Pa}\right), L$ is the length of the substrate with the adhesive $(\mathrm{m}), \delta$ is the substrate thickness $(\mathrm{m})$, and $\delta^{*}$ is the adhesive thickness $(\mathrm{m})$.

At the initial stage, a coating with thickness $\delta=0.1-0.2 \mathrm{~mm}$ on a steel substrate was formed by the spray method. The parameters of the substrate were: total length $l=100 \mathrm{~mm}$, working length $l_{0}=80 \mathrm{~mm}$, thickness $\delta=0.2 \mathrm{~mm}$. At the next step, during the polymerization process, the chemical bonds between the adhesive and the substrate are forming, which involves the occurrence of residual stresses in the coating. This leads to the deflection of the console up (in the form of a substrate with a coating), as the dominant in this case is the tensile stress. The value of this deflection $(H)$ was determined after complete crosslinking of the material in the form of a protective coating (for a duration of 72 hours). Flexural stresses at bending and the modulus of elasticity at bending were determined in accordance with ASTM D $790-03$. The dimensions of the testing specimens were: length $l=120 \pm 2 \mathrm{~mm}$, width $b=15 \pm 0.5 \mathrm{~mm}$, height $h=10 \pm 0.5 \mathrm{~mm}$ [11]. The impact strength 
was determined by the Charpy method according to ASTM D6110 - 18. This method is based on a test in which a specimen placed on two supports is subjected to a pendulum impact, the line of impact being midway between the supports and directly opposite the notch (in the case of notched specimen). The dimensions of the testing specimens were: $(63.5 \times 12.7 \times 12.7) \pm 0.5 \mathrm{~mm}$. The distance between the supports was $40 \pm 0.5 \mathrm{~mm}$. The deviation of values of adhesive and physical and mechanical properties of $\mathrm{CM}$ was $4-6 \%$ from nominal during the study.

\section{RESULTS AND DISCUSSIONS}

It has been experimentally established that the adhesion strength at break of the epoxy matrix modified by USP is $\sigma_{\mathrm{a}}=24.8 \mathrm{MPa}$ (Figure 1). The introduction of SICM particles $(d=15-18 \mu \mathrm{m})$ into the epoxy binder leads to a monotonic increase in the adhesive strength of the composite. It is shown (Figure 1, curve 1) that the maximum in the "adhesive strength at break-filler amount" curve was observed at content of particles of $q=0.5$ wt. $\%$ by 100 wt. $\%$ of ED-20 (hereinafter wt. $\%$ are given per $100 \mathrm{wt} . \%$ of epoxy resin ED-20). The adhesive strength of the material increases from $\sigma_{\mathrm{a}}=24.8 \mathrm{MPa}$ (epoxy matrix) to $\sigma_{\mathrm{a}}=44.7 \mathrm{MPa}$ at this introduction. Further increase in the particle content leads to a deterioration of the adhesive properties of epoxy composites. It has been proved (Figure 1) that the content increase of particles amount to $q=2.0$ wt.\% promotes the $\mathrm{CM}$ formation. The adhesive strength of such $\mathrm{CM}$ decreases from $\sigma_{\mathrm{a}}=44.7 \mathrm{MPa}$ (for $\mathrm{CM}$ with filler content of $q=0.5$ wt. $\%$ ) to $\sigma_{\mathrm{a}}=33.2 \mathrm{MPa}$. Based on the above experimental results, it was considered that the further increase of the SICM amount in the epoxy composite is not advisable, since the adhesive properties of the materials monotonically deteriorate.

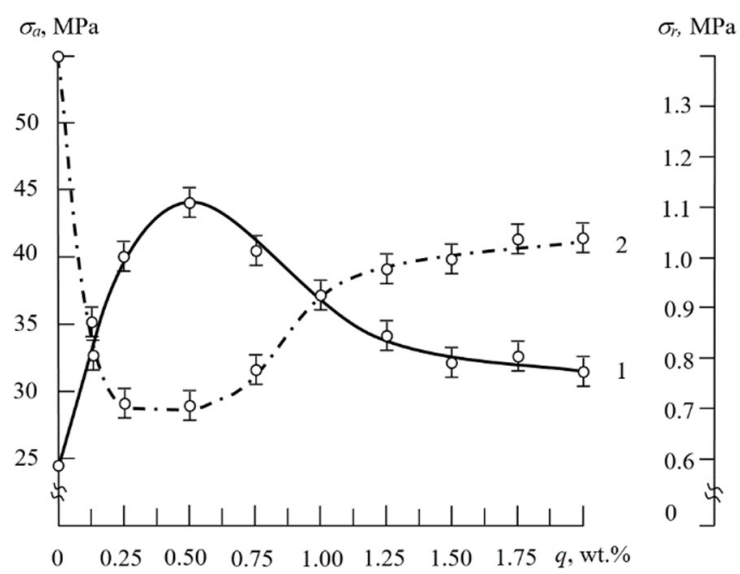

Fig. 1. Dependence of adhesive strength and residual stresses in $\mathrm{CM}$ on the content of SICM particles: 1 - adhesive strength at break $\left(\sigma_{\mathrm{a}}\right) ; 2$ - residual stresses $\left(\sigma_{\mathrm{r}}\right)$. substrate material - steel.

The obtained experimental results allow stating the efficiency of using the SICM for the formation of CM on the basis of epoxy binder. Authors in $[8,9]$ showed that before the synthesis of filler particles at the initial stage they formed a mechanical mixture of powders at a predetermined content:
$\mathrm{Fe}(75 \%)+\mathrm{Ti}(25 \%)$. In the process of high-voltage electric discharge according to predetermined modes, a synthesized powder is formed, which contains components of the following composition: $\mathrm{Fe}(70 \%)+\mathrm{TiC}(25 \%)+\mathrm{Fe}_{3} \mathrm{C}(5 \%)$. It was proved, that the improvement of adhesion characteristics of materials as a result of the loading of active dispersed particles into the epoxy oligomer is presented. It was assumed that the active centers of $\mathrm{Fe}, \mathrm{TiC}$ and $\mathrm{Fe}_{3} \mathrm{C}$, which are contained both in the volume and on the surface of the dispersed phase during the polymerization process interact with the segments and pendent groups $(\mathrm{OH}-, \mathrm{CH}-, \mathrm{C}=\mathrm{O})$ of the epoxy oligomer. At the same time, the degree of crosslinking of the three-dimensional polymer net increases, which improves the adhesive properties of CM. In addition, authors in [8,9] proved that, after the synthesis, on the surface of the particles areas, titanium and iron carbides are localized, which are mainly activators of physical and chemical interfacial bonds in the structure of materials. At the same time, it should be noted that the maximum number of chemical bonds per volume unit of the polymer was observed at a critical content of dispersed particles in the amount of $q=0.5 \mathrm{wt} . \%$. This explains the highest values of adhesive strength of composites with such a filler content among the entire range of investigated materials.

It is known [12] that the occurrence of residual stresses in polymer composites is one of the determining criteria for the durability of protective coatings, including anti-corrosion coatings, especially in the transport industry. Therefore, in the context of adhesion tests, it was considered necessary to investigate the value of residual stresses in the formed coatings depending on the content of the SICM. It is established (Figure 1 , curve 2) that the initial epoxy matrix is characterized by residual stresses $\sigma_{\mathrm{r}}=1.4 \mathrm{MPa}$. The introduction of SICM particles at low content $(q=0.2-0.5 \mathrm{wt} . \%)$ provides a decrease in residual stresses from $1.4 \mathrm{MPa}$ (for epoxy matrix) to $0.7 \mathrm{MPa}$. Further increase in the particle content ( $q=0.7-2.0 \mathrm{wt} . \%)$ leads to an increase in the value of residual stresses in the protective coatings to $\sigma_{\mathrm{r}}=0.8-1.0 \mathrm{MPa}$. Comparing the values of adhesive strength and residual stresses depending on the content of particles, we can state the following: The highest values of adhesive strength $\left(\sigma_{\mathrm{a}}=44.7 \mathrm{MPa}\right)$ among the whole range of test materials is a composite containing filler in the amount of $q=0.5 \mathrm{wt} . \%$. At the same time, such a material is characterized by the lowest residual stresses, which are $\sigma_{\mathrm{r}}=0.7 \mathrm{MPa}$. This indicates that the developed composite and the protective coating based on it can be used quite effectively to improve the performance of parts that work not only under static but also dynamic loads. Hence, the optimal content of the SICM for the formation of epoxy protective coating with maximum adhesion characteristics and low residual stresses was determined. It is proved that at the introduction of the powder in the amount of $q=0.5 \mathrm{wt} . \%$ a material with the following properties is formed: adhesive strength at break $\sigma_{\mathrm{a}}=44.7 \mathrm{MPa}$ and residual stresses $\sigma_{\mathrm{r}}=0.7 \mathrm{MPa}$. This provides an increase in the adhesion strength at break by 1.8 times and a decrease in residual stresses by 2.0 times compared with the ultrasonically modified epoxy matrix.

It should be noted that from a scientific and practical point of view it is interesting to study not only the adhesive properties of materials and residual stresses depending on the 
content of SICM particles, but also the dynamics of mechanical characteristics at different amounts of active filler. Therefore, at the next stage, physical and mechanical properties of epoxy composites filled with SICM were studied. In particular, the modulus of elasticity and flexural stresses at bending and impact strength of the developed materials were analyzed. It has been experimentally established (Figure 2, curve 1) that the modulus of elasticity of the epoxy matrix modified by UPS is $E=2.8 \mathrm{GPa}$. The introduction of filler particles at low content $(q=0.2-0.5$ wt.\%) does not change this characteristic of the $\mathrm{CM}$, since the modulus of elasticity at bending is $2.6-2.8 \mathrm{GPa}$ (values within experimental errors). Further increase in the content of particles from $0.7 \mathrm{wt} \%$ to $2.0 \mathrm{wt} . \%$ leads to a deterioration of the elastic properties of the CM. In particular, it was shown (Figure 2, curve 1) that at such loading the modulus of elasticity decreases from $2.8 \mathrm{GPa}$ (for epoxy matrix) to 2.2-2.4GPa. Note that the modulus of elasticity characterizes not only the elastic characteristics of materials, but also their brittleness. From another point of view, high values of the modulus of elasticity indirectly indicate increased values of residual stresses in materials and a significant stress state in their structure. It can be a cause of premature failure of composites, especially under the action of shock loads. Taking into account the modulus of elasticity, it can be argued that the effective materials are composites filled with SICM particles in amounts of $q=0.2-0.5 \mathrm{wt} . \%$.

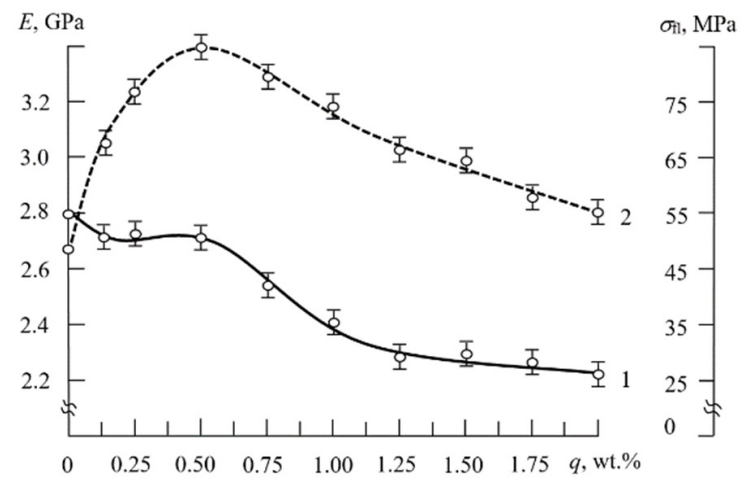

Fig. 2. Dependence of physical and mechanical properties of epoxy CM at the SICM content: 1 - elasticity modulus at bending $(E) ; 2$ - flexural stresses at bending $\left(\sigma_{f l}\right)$

According to the studied results of the dynamics of the values of flexural stresses at bending from the filler amount, the following can be stated: It was established (Figure 2, curve 2) that the value of the flexural stresses of the epoxy matrix modified by USP was $\sigma_{f}=48.0 \mathrm{MPa}$. It was proved that the introduction of SICM particles at low content $(q=0.2-0.5$ wt.\%) leads to a monotonic increase in the value of flexural stresses from $48.0 \mathrm{MPa}$ (for the original matrix) to $67.2-84.9 \mathrm{MPa}$. The maximum in the "flexural stresses at bending-filler content" curve was observed at $0.5 \mathrm{wt} . \%$ SICM content. The magnitude of the flexural stresses for such a material was $\sigma_{\mathrm{fl}}=84.9 \mathrm{MPa}$. Further increase in the content of particles leads to a deterioration of the cohesive properties of composites. It has been shown (Figure 2, curve 2) that the loading of particles at a content of $q=0.7-2.0 \mathrm{wt} . \%$ into the CM leads to a decrease in the flexural stresses from $\sigma_{\mathrm{fl}}=84.9 \mathrm{MPa}$ (for materials with a content of SICM 0.5 wt. $\%)$ to $\sigma_{\mathrm{fl}}=55.0-71.1 \mathrm{MPa}$. The magnitude of the flexural stresses at bending indirectly indicates the plastic properties of the materials. As shown above, the modulus of elasticity, which characterizes the materials brittleness, for composites at a $0.5 \mathrm{wt} \%$. particle content is almost no different from the similar characteristic for the epoxy matrix. At the same time, the values of flexural stresses at bending of such CM are almost 2 times higher than the similar values of the matrix. Based on this, the effectiveness of the additives introduction at such content to improve the elastic-plastic properties of composites for different functional purposes can be argued.

It should be noted that one of the problems of modern materials science is the creation of materials and protective coatings based on them, which can be operated under the influence of static and shock loads. Therefore, it was considered necessary to investigate the impact strength of materials with different filler content. It was experimentally found (Figure 3 ) that the impact strength of the epoxy matrix modified by UPS was $W=7.4 \mathrm{~kJ} / \mathrm{m}^{2}$. Extreme dependence in the " $W-q$ " values was observed when the SICM particles were loaded into the binder. Maximum values among the whole spectrum of the studied materials were observed for CM with a 0.5 wt. $\%$ content of particles. The formation of such $\mathrm{CM}$ provides an increase in impact strength from $7.4 \mathrm{~kJ} / \mathrm{m}^{2}$ to $13.0 \mathrm{~kJ} / \mathrm{m}^{2}$. Further increase in the particles content leads to a decrease in the impact strength of epoxy composites. In order to analyze the mechanism of destruction of materials under the influence of shock loads in detail, their fracture structure was additionally investigated by optical microscopy. It should be noted that the fracture surface of the specimens was analyzed with pre-selected content of dispersed particles in $\mathrm{CM}$ : $q=0.2$ wt. $\%, q=0.5$ wt. $\%$, and $q=1.0$ wt. $\%$.

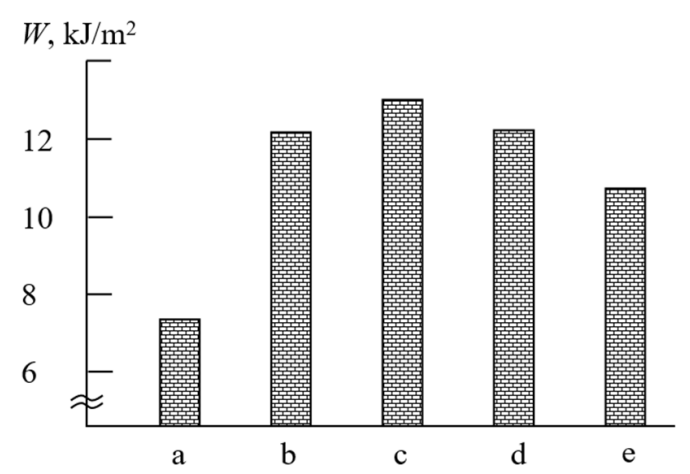

Fig. 3. The dependence of the impact strength $(W)$ on the SICM content (q) in CM: (a) matrix (control specimen), (b) 0.2 wt.\%, (c) 0.5 wt.\%, (d) 1.0 wt.\%, (e) 1.5 wt.\%

It is shown (Figure 4(a)) that the destruction of specimens filled with SICM particles at a content of $0.2 \mathrm{wt} . \%$, occurs in an almost straight line. This is evidence that the material does not sufficiently resist external loads, and the crack propagation front is rectilinear. On the fracture surface of such samples, a grid of chipping lines is visible (Figure 4(b)-(c)), depressions and craters are observed, which is evidence of a sufficiently 
tense state in such systems. It can be argued about the low reliability in the operation of such materials.
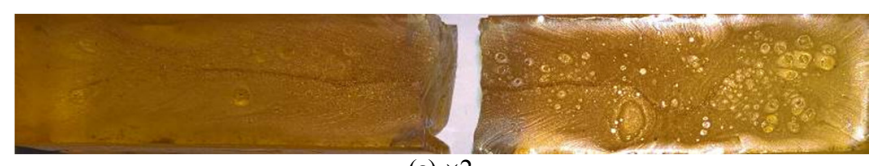

(a) $\times 2$

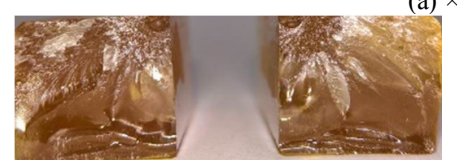

(b) $\times 4$

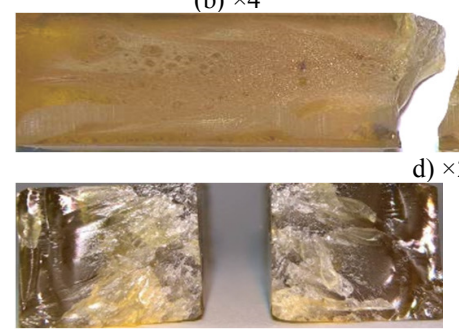

(e) $\times 4$
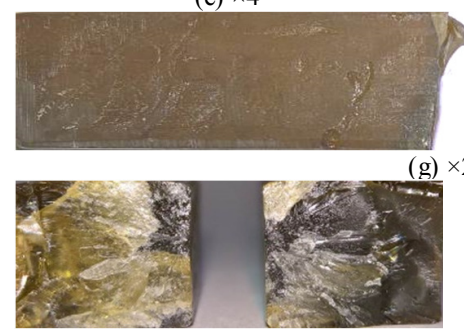

(h) $\times 4$

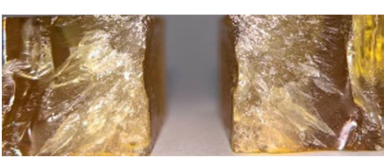

(c) $\times 4$

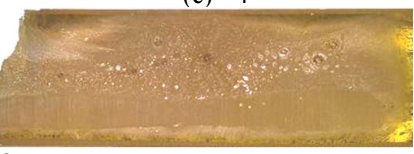

2

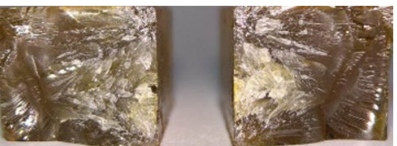

(f) $\times 4$

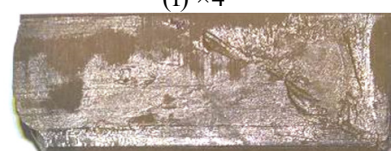

$\times 2$

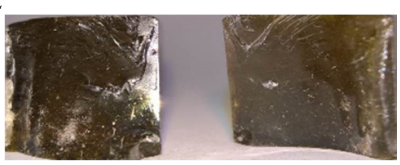

(i) $\times 4$
Fig. 4. Fractograms of $\mathrm{CM}$ fracture at different content of microdisperse filler SICM $q$ per 100 wt.\% of epoxy oligomer ED-20: (a)-(c) 0.2 , (d)-(f) 0.5 , (g)-(i) 1.0 .

On the contrary, for 0.5 wt. $\%$ content of particles the curvilinear nature of the fracture surface was observed (Figure 4(d)). This allows to state about the increased cohesion characteristics of composites with filler at such content. The presence of particles in such CMs increases the resistance to the propagation of cracks during impact, as a result of which the trajectory of destruction of the specimens is wavy. Additional analysis of the images shown in Figure 4(d)-(e) allows to state the existence of a stress state in such systems, but the nature of the fracture is viscous, with noticeable petalshaped inclusions. This suggests the existence of areas with improved cohesive strength, which increases the durability of such materials during operation in critical conditions under the influence of shock loads. Analysis of the fracture surface of the specimens of the CM at $1.0 \mathrm{wt}$ \% particle content allows assert about the rectilinear character of crack propagation during the destruction of materials (Figure $4(\mathrm{~g})$ ). At the same time, it should be noted that the fracture surface of such specimens is characterized by a tightly packed structure (Figure 4(h)-(i)), which indicates the improved cohesive properties of such materials. The use of such composites in the operation of equipment under the influence of shock loads can be argued.

\section{CONCLUSION}

The optimal content of microdispersed filler of iron-carbide mixture synthesized by high-voltage electric discharge $(d=15-18 \mu \mathrm{m})$ for the formation of epoxy protective coating with improved adhesive and cohesive properties and insignificant residual stresses to increase the service life of transport parts was established. It has been found that when introducing particles of iron-carbide mixture in the amount of 0.5 wt. $\%$ by 100 wt. $\%$ of ED-20 epoxy oligomer, a material was formed with adhesive strength at break $\sigma_{\mathrm{a}}=44.7 \mathrm{MPa}$ and residual stress $\sigma_{\mathrm{r}}=0.7 \mathrm{MPa}$. This provides an increase, compared to the epoxy matrix modified by ultrasonic processing of the adhesion strength at break by 1.8 times and a decrease in residual stresses by 2.0 times. It is proven that the active centers of $\mathrm{Fe}, \mathrm{TiC}$ and $\mathrm{Fe}_{3} \mathrm{C}$, which are contained both in the volume and on the surface of the dispersed phase during the polymerization process, interact with the segments and pendent groups $(\mathrm{OH}-, \mathrm{CH}-, \mathrm{C}=\mathrm{O})$ of the epoxy oligomer. This increases the degree of crosslinking of the three-dimensional polymer net, which improves the adhesive properties of the composites. This is due to the fact that on the surface of the particles after synthesis areas of titanium and iron carbides, which are mainly activators of the formation of physical and chemical interfacial bonds in the structure of materials are localized.

It has been established that the introduction of powder mixture particles in the amount of $q=0.5 \mathrm{wt} . \%$ by $100 \mathrm{wt} . \%$ of epoxy oligomer ED-20 provides the formation of a material with the following properties: modulus of elasticity at bending $E=2.7 \mathrm{GPa}$, flexural stress at bending $\sigma_{\mathrm{ff}}=84.9 \mathrm{MPa}$, and impact strength $W=13.0 \mathrm{~kJ} / \mathrm{m}^{2}$. The formation of such a material provides a 1.8-times increase in the flexural stresses at bending and impact strength compared to the epoxy matrix modified by USP, while the modulus of elasticity was closely unchanged. For composites at a particle content in the amount of $q=0.5$ wt. $\%$ the curvilinear nature of the fracture surface was observed. This allows to state about the increased cohesion characteristics of materials at such filler content. The presence of particles in such a composite increases the resistance to the crack propagation during impact, as a result of which the trajectory of destruction of the specimen is wavy. This allows to assert the existence of areas with improved cohesive strength, which increases the durability of such materials during operation in critical conditions of impact loads.

\section{REFERENCES}

[1] Y. Zhan, J. Zhang, X. Wan, Z. Long, S. He, and Y. He, "Epoxy composites coating with $\mathrm{Fe} 3 \mathrm{O} 4$ decorated graphene oxide: Modified bio-inspired surface chemistry, synergistic effect and improved anticorrosion performance," Applied Surface Science, vol. 436, pp. 756-767, Apr. 2018, doi: 10.1016/j.apsusc.2017.12.095.

[2] D. Liu, W. Zhao, S. Liu, Q. Cen, and Q. Xue, "Comparative tribological and corrosion resistance properties of epoxy composite coatings reinforced with functionalized fullerene C60 and graphene," Surface and Coatings Technology, vol. 286, pp. 354-364, Jan. 2016, doi: 10.1016/j.surfcoat.2015.12.056.

[3] D. Matykiewicz, M. Barczewski, D. Knapski, and K. Skórczewska, "Hybrid effects of basalt fibers and basalt powder on thermomechanical properties of epoxy composites," Composites Part B: Engineering, vol. 125, pp. 157-164, Sep. 2017, doi: 10.1016/j.compositesb.2017.05.060.

[4] V. A. Kioussis, M. Danikas, D. D. Christantoni, G. E. Vardakis, and A. Bairaktari, "Electrical Trees in a Composite Insulating System Consisted 
of Epoxy Resin and Mica: The Case of Multiple Mica Sheets For Machine Insulation," Engineering, Technology \& Applied Science Research, vol. 4, no. 4, pp. 662-668, Aug. 2014.

[5] M. Danikas, D. Verginadis, and R. Sarathi, "Study of The Phenomena of Surface Discharges and Flashover in Nanocomposite Epoxy Resin under the Influence of Homogeneous Electric Fields," Engineering, Technology \& Applied Science Research, vol. 9, no. 4 SE-Articles, pp. 4315-4321, Aug. 2019.

[6] A. V. Buketov et al., "Dynamics of destruction of epoxy composites filled with ultra-dispersed diamond under impact conditions," Mechanics of Advanced Materials and Structures, vol. 27, no. 9, pp. 725-733, May 2020, doi: 10.1080/15376494.2018.1495788.

[7] M. V. Kindrachuk, A. I. Vol'chenko, D. A. Vol'chenko, D. Y. Zhuravlev, and V. M. Chufus, "Electrodynamics of the Thermal Contact Friction Interaction in Metal-Polymer Friction Couples," Materials Science, vol. 54, no. 1, pp. 69-77, Jul. 2018, doi: 10.1007/s1 1003-0180159-2.

[8] O. N. Sizonenko et al., "Variation in the particle size of FE-TI-B4C powders induced by high-voltage electrical discharge," Powder Metallurgy and Metal Ceramics, vol. 51, no. 3-4, pp. 129-136, Jul. 2012, doi: 10.1007/s11106-012-9407-4.

[9] O. Syzonenko, E. Sheregii, S. Prokhorenko, and A. Torpakov, "Method of preparation of blend for aluminium matrix composites by high voltage electric discharge," Machines. Technologies. Materials., vol. 11, no. 4, pp. 171-173, 2017.

[10] I. H. Dobrotvor, P. D. Stukhlyak, and A. V. Buketov, "Determination of the ranges of the optimal content of a dispersed filler in epoxy composites," Materials Science, vol. 45, no. 6, pp. 790-797, Nov. 2009, doi: 10.1007/s1 1003-010-9244-x.

[11] A. V. Buketov, N. A. Dolgov, A. A. Sapronov, V. D. Nigalatii, and N. V. Babich, "Mechanical Characteristics of Epoxy Nanocomposite Coatings with Ultradisperse Diamond Particles," Strength of Materials, vol. 49, no. 3, pp. 464-471, 2017, doi: 10.1007/s11223-017-9888-y.

[12] A. V. Buketov, P. D. Stukhlyak, I. G. Dobrotvor, N. M. Mytnyk, and N. A. Dolgov, "Effect of the nature of fillers and ultraviolet irradiation on the mechanical properties of epoxy composite coatings," Strength of Materials, vol. 41, no. 4, pp. 431-435, Jul. 2009, doi: 10.1007/s11223009-9136-1. 